\title{
Cardiothoracic-themed core surgical training programs in Scotland
}

\author{
Simon Lammy, MRCS (Ed)
}

Cardiothoracic surgery generates an impression that only the most committed should pursue it. The book TSRA Review of Cardiothoracic Surgery (Thoracic Surgery Residents Association) is organized around topics core surgical trainees (ie, residents) are expected to understand and master, particularly as surgical selection and training has undergone recent change. (J Thorac Cardiovasc Surg 2013;146:504-5)

Surgical selection has undergone a dramatic change in Britain. Successful selection demands thorough preparation, and aspiring cardiothoracic surgeons must start demonstrating commitment in medical school. Medical graduates in Britain undergo a 2-year competitively selected internship program during which they complete 6 rotations of 4 months' duration. The first year is foundation year 1 , and the second year is foundation year $2 .{ }^{1}$ Both incorporate exposure to acute and chronic specialties preparing the trainee for competitive selection to a surgical training program. Surgical training is split into 2 stages: basic (core) surgical training and higher (specialty) surgical training.

Core surgical training lasts for 2 years. Each program is specialty themed, and a trainee can expect up to 12 months in cardiothoracic surgery. ${ }^{2}$ This allows a trainee to demonstrate commitment and is crucial for entry into an extremely competitive higher surgical training program in cardiothoracic surgery. Higher surgical training lasts 6 years (ST3-ST8), guaranteeing a trainee career progression in cardiothoracic surgery as a result of attainment of a national training number. Higher surgical training develops expertise in cardiothoracic surgery, preparing a trainee to acquire a certificate of completion of training. This makes a trainee eligible to become a consultant.

Medical graduates who are intent on pursuing a cardiothoracic career ensure that they obtain a surgically biased internship program. This enables exposure to clinical and academic aspects of a surgical career and provides invaluable preparation for surgical selection. More astute trainees ensure their internship rotations include medical specialties in cardiology and respiratory medicine and surgical rotations in cardiothoracic and general surgery. This provides grounding in both the medical and surgical treatment of diseases particular to the thorax. Surgical selection occurs

From the Department of Cardiothoracic Surgery, Royal Infirmary of Edinburgh, Edinburgh, United Kingdom.

Disclosures: Authors have nothing to disclose with regard to commercial support.

Received for publication Nov 8, 2012; accepted for publication April 19, 2013; available ahead of print June 21, 2013.

Address for reprints: Simon Lammy, MRCS (Ed), CT1 Cardiothoracic Surgery, Core Surgical National Recruitment Office Trainee Representative 2013, Department of Cardiothoracic Surgery, Royal Infirmary of Edinburgh, 51 Little France Crescent, Edinburgh EH16 4SA, United Kingdom (E-mail: lammy@doctors.org.uk).

$0022-5223 / \$ 36.00$

Copyright (c) 2013 by The American Association for Thoracic Surgery http://dx.doi.org/10.1016/j.jtcvs.2013.04.039 midway through foundation year 2. Selection from internship to a core surgical training program is conducted through a national selection process. ${ }^{3}$

Interns demonstrate clinical commitment by completing basic surgical and critical care courses. These are conducted at 1 of the 4 Royal Colleges in Britain, permitting the trainee structured educational learning. Aspiring cardiothoracic trainees obtain professional qualifications, such as Advanced Life Support ${ }^{4}$ and Advanced Trauma Life Support, ${ }^{5}$ as approved by the Resuscitation Council (UK) and the Royal College of Surgeons of England. ${ }^{6}$ In addition, trainees need to acquire a broad surgical logbook incorporating common surgical procedures.

Talented interns demonstrate academic commitment through completion of clinical audit and surgical research. Submission of abstracts for presentation at national (eg, Society of Cardiothoracic Surgery in Great Britain and Ireland) and international (eg, European Association of Cardiothoracic Surgeons) conferences, alongside publications in reputable journals, acts to distinguish candidates. One crucial step is passing intercollegiate surgical examinations and becoming a member of the Royal College of Surgeons. ${ }^{7}$ This is an absolute requirement to progress from core to higher surgical training, but determined physicians obtain membership during their internship.

The examination to become a member of the Royal College of Surgeons is composed of 2 parts. Part A contains 2 written papers that examine basic sciences (eg, anatomy) and clinical surgical acumen (eg, clinical vignettes). Part $\mathrm{B}$ is an objective structured clinical examination consisting of up to 18 assessed non-practical and practical stations. Completion enables a physician to undergo a unique British surgical privilege to become a mister. Managerial commitment includes leadership experience. Shrewd trainees do not just obtain professional qualifications, but also pass instructor training (eg, Advanced Life Support instructor courses). This provides opportunities to teach established courses, which develop and refine teaching abilities.

Surgical aptitude is assessed on both a generic application form and an interview. ${ }^{3}$ At the interview, candidates are assessed across several stations. A portfolio station enables an interrogative analysis of a surgical portfolio and commitment to surgery. A clinical station assesses clinical vignette analysis and management plan formulation. A management 

Abbreviations and Acronyms
ST3 $=$ higher surgical training year 3
ST8 $=$ higher surgical training year 8

station tests clinical governance. The highest-scoring candidate acquires his or her first choice of a core surgical training program and can pick one themed in a specialty of his or her choice (eg, cardiothoracic surgery). Scoring higher to obtain a specialty-specific core surgical training program can influence selection for entry into higher surgical training in that specialty. Competition ratios of 3.8:1 exist across core surgical selection. ${ }^{8}$

Cardiothoracic-themed core surgical training programs are highly sought after. Deaneries intent on providing as much exposure to the clinical and academic aspects of cardiothoracic surgery ensure their core surgical trainees on a cardiothoracic-themed core surgical training program have at least 12 months in the specialty. ${ }^{2}$ This enables thorough preparation for selection to higher surgical training (ie, ST3). Core surgical trainees in cardiothoracic surgery must be prepared to acquire a clinical and academic grounding in the specialty. ${ }^{9}$

It can be daunting undertaking basic training in cardiothoracic surgery, and one invaluable resource is the book TSRA Review of Cardiothoracic Surgery (Thoracic Surgery Residents Association). ${ }^{10}$ This book is organized around topics core surgical trainees (ie, residents) are expected to understand and master. It is concise and explores themes in a tutorial manner, enabling acquisition and retention of the fundamentals of cardiothoracic practice. It has proved to be a little interesting book enabling surgical trainees to digest the basic and most pertinent facts for their daily learning. In Scotland, basic texts are often highly condensed scripts of established reference texts pitched for higher surgical trainees. Consequently, a book composed by residents for residents is highly appreciated by those wanting to master the basic principles.
Cardiothoracic surgery generates an impression that only the most committed should pursue it. This impression discourages many potential applicants before the process has even begun, leaving a cohort of extremely talented people competing for 20 to 26 dedicated places in the United Kingdom for higher surgical training through a national selection process. ${ }^{9}$ Although possessing a lower ratio than some specialties in numerical terms (eg, $\sim 4: 1$ ), the base competitiveness of the applicant is much higher.

Once appointed to an ST3 post, subsequent attainment of a certificate of completion of training depends on demonstrating significant clinical and academic experience. One absolute requirement is passing higher surgical examinations and becoming a fellow of the Royal College of Surgeons in cardiothoracic surgery. Such an accomplishment represents a triumph of commitment, but the foundation must start somewhere: the TSRA Review of Cardiothoracic Surgery is an excellent book that helps a trainee cut into the learning curve.

\section{References}

1. The UK Foundation Programme Office. The UK foundation programme curriculum. Available at: http://www.foundationprogramme.nhs.uk/pages/home. Accessed June 12, 2013.

2. The Joint Committee on Surgical Training. Intercollegiate surgical curriculum project. Available at: http://www.jchst.org/. Accessed June 12, 2013.

3. The Core Surgery National Recruitment Office. Core Surgical Training Applicant Guide. Available at: http://www.surgeryrecruitment.nhs.uk/sites/ surgeryrecruitment/files/CST\%202013\%20Applicant\%20Guide\%20v13.pdf. Accessed June 12, 2013.

4. Resuscitation Council (UK). Advanced Life Support. 6th ed. London, UK: Resuscitation Council (UK); 2011.

5. American College of Surgeons. Advanced Trauma Life Support. 8th ed. Chicago, IL: American College of Surgeons; 2011.

6. Royal College of Surgeons of England. Advanced Trauma Life Support (ATLS). Available at: http://www.rcseng.ac.uk/courses/course-search/atls.html. Accessed June 12, 2013.

7. Royal College of Surgeons of Edinburgh. Your Guide to the MRCS. Available at: http://www.rcsed.ac.uk/media/221088/rcsed_mrcs\%20guide\%20update2013_ web.pdf. Accessed June 12, 2013

8. Jacques H. Specialty training competition stabilises as applications and posts rise. BMJ Careers. 2012;344:1.

9. McCormack D, Smith S, Bhudia S, Osgood V, Barnard S. A career in cardiothoracic surgery. BMJ Careers. 2010;340:1.

10. Mery CM, Turek JW. TSRA Review of Cardiothoracic Surgery. Charleston, SC CreateSpace; 2011. 